\title{
KNOWLEDGE MODELING FOR HERITAGE CONSERVATION PROCESS: FROM SURVEY TO HBIM IMPLEMENTATION
}

\author{
F. Di Stefano ${ }^{1}$, A. Gorreja ${ }^{1}$, E.S. Malinverni ${ }^{1}$, C. Mariotti ${ }^{1 *}$ \\ ${ }^{1}$ Università Politecnica delle Marche, Department of Construction, Civil Engineering and Architecture (DICEA), Ancona, Italy \\ \{f.distefano,a.gorreja\}@pm.univpm.it; $\{$ e.s.malinverni, chiara.mariotti\}@univpm.it
}

\author{
Commission VI, WG VI/4
}

KEY WORDS: Cultural Heritage, Geomatics, Ontology, 3D Modeling, HBIM, Conservation, knowledge-led strategy.

\begin{abstract}
:
This paper aims to develop a strategy for architectural knowledge modeling in order to actively support the built heritage conservation process by fostering collaboration among stakeholders and interoperability between datasets. The integration of two modeling systems, one ontology-based and one in BIM environment, seems to be the right way to meet this objective: the former is rather exhaustive to represent the semantic contents of conservation activities, especially non-geometrical data, the latter is absolutely suitable to represent the logic of the construction, above all geometrical-constructive aspects typical of any architectural organism. Thus, this study proposes a side-by-side approach to synchronize these different ways of representing reality by managing the complexity of cultural heritage on the one hand and of technology tools, such as information systems, on the other. The proposed methodology was tested on the city walls of San Ginesio (Macerata, Italy) and included different steps considering the in-use technologies (notably geomatics and information technologies) as key enablers to acquire, hierarchically order, model and enrich the knowledge of that heritage site. The result is a knowledge-led strategy moving from survey to HBIM implementation, as a way to enhance representation and management in architectural heritage processes.
\end{abstract}

\section{INTRODUCTION}

The need to make the heritage conservation and enhancement processes coordinated and planned has been established at a theoretical and legislative level for several years now.

In Italy, in particular, the basis of such a methodological approach are stated in art.29 of the D.Lgs. 42/2004 - Codice dei Beni Culturali e del Paesaggio, encouraging a conservation practice ensured by «a coherent, coordinated and planned activity of study, prevention, maintenance and restoration». In addition, art. 3 of the D.M. 154/2017 - Regolamento concernente gli appalti pubblici di lavori riguardanti i beni culturali tutelati explicitly refers to the above-mentioned article and clarifies that public interventions on cultural heritage have to be implemented «according to the timescales, priorities and recommendations deriving from the criterion of planned conservation».

Heading in this direction means developing an operative methodology able to collect, hierarchically organize, but also interconnect and manage heterogeneous data (different sources, contents, scales of representation, levels of detail and development, etc.) related to historical architectures and sites in the medium-long term, ensuring accessibility and shareability of information among stakeholders during the various phases of the conservation process.

The implementation of innovative digital technologies, from survey to BIM (Building Information Modeling), can offer significant chances to support both the crucial but radical change of processes and tools, which are traditionally available to the architect-restorer, and the collaboration with experts working in cross-disciplinary fields.

Starting from these critical issues, this study intends to reflect on the theme of heritage knowledge as the backbone of a double transition: the first one from $2 \mathrm{D}$ to $3 \mathrm{D}$ heritage representation and towards HBIM (where 'H' stands for Historic or sometimes Heritage), the second one from the restoration project to conservation process (Della Torre, 2012; Della Torre 2017).

To exploit the potential of Information and Communication Technology (ICT) while respecting the discipline of heritage protection and its specificities, the approach to artefacts (survey, modeling and data enrichment) has to be based on knowledge as a guiding principle; in this sense, it is possible to talk about 'knowledge modeling' as several authors have recently highlighted (Acierno 2017; Acierno et al., 2017; Fiorani 2017).

\section{OBJECT AND AIM}

In this perspective, this paper aims to develop a strategy for architectural knowledge modeling in order to actively support the heritage conservation process by fostering collaboration among stakeholders and interoperability between datasets. It proposes a side-by-side approach to synchronize two different ways of representing reality, which do not yet automatically interact: one ontology-based that is rather exhaustive to represent the semantic contents of conservation activities, especially non-geometrical information but data regarding building history, evolutionary phases, physical consistency and state of conservation, and one in BIM environment absolutely suitable to represent the logic of the construction, above all geometrical-constructive aspects typical of any architectural organism.

Such a strategy was tested on the city walls of San Ginesio (Macerata, Italy). Several reasons validated this case study: first of all, the city walls were affected by the seismic events occurred in 2016 causing structural damages, hence conservation planning and long-term management are now a prerogative of the local administration with which the

* Corresponding author 
Università Politecnica delle Marche (DICEA) has already signed a research agreement. Moreover, the city walls are at the same time a complex urban organism, but also a quite simple architecture if they are intended as a system of curtain walls and towers making it easier to test this strategy. A special focus of this paper is the decay analysis for the conservation project of the main town gateway tower, known as Porta Picena, and the adjacent curtain wall.

\section{STATE OF THE ART}

In the last few years, the use of BIM technology in the AEC (Architecture, Engineering and Construction) industry has improved several working processes including design, construction and management for new buildings, but its application in the field of existing buildings (Arayici, 2008; Volk et al., 2014), and in particular of historical architecture (Simone et al., 2014), still shows some limitations.

In fact, the new ICTs offer undisputed advantages to the collection and management of different kinds of information and data; nevertheless, they also have crucial limitations and can cause undesired consequences, which are often inherent to the development of digital virtual models that struggle to detect and represent real complex architectural structures, especially if they are ancient and belonging to the Cultural Heritage.

Working on the architectural heritage requires the control of both analytical-scientific phases, such as the analysis of its geometry, material consistency, construction techniques or decay phenomena, and critical-interpretative phases related to the understanding of its material and immaterial values - for instance, its authenticity, identity and integrity to name but a few. These latter are aspects that more than others risk being sacrificed when, in (H)BIM environment, experts use parametric software with default functionalities from which it is not easy to deviate.

Such a condition implies on the one hand the impossibility of representing the uniqueness of the built heritage, deeply related to its history and historical events, on the other hand the lack of semantically enriching the virtual model with its interpretative context that can be deduced only through a well-structured system of knowledge-led investigations.

Since HBIM was first introduced (Murphy et al., 2009; Dore, Murphy, 2012), attempts to overcome these matters have multiplied, bringing this research topic to the centre of the current scientific debate. Nowadays, a significant literature has been produced documenting the state of the art on this subject (Logothetis et al., 2015; Dore, Murphy, 2017): existing and ongoing studies prove the need to make this technology perfectible by updating and adapting it to the features of built heritage in order to meet specific programmatic objectives.

Over the years, some research projects have been focused on optimizing modeling times (Biagini et al., 2016), integrating data from laser scanner survey into BIM also by the creation of parametric objects directly from the $3 \mathrm{D}$ point cloud, on defining the most suitable levels of accuracy of the parametric model and characterizing it with data related to materials, construction techniques and stratigraphy (Garagnani, Manferdini, 2013; Spallone et al., 2016; Malinverni et al., 2019), on testing the possibilities for a new storytelling (Di Giulio et al., 2019; Banfi, Oreni, 2020) and, last but not least, on building adequate forms of semantic enrichment both on an architectural and urban scale through the use of ontologies and geographic information systems (Quattrini et al., 2017; Chiabrando et al., 2018; Acierno, Fiorani, 2019; Simeone et al., 2019).

Compared to the aim of this paper, the most interesting researches are those which have tried to overcome the idea of HBIM as a simple repository of complex data, conceiving it rather as «a hub for supporting integrated documentation of heritage artefacts» (Simeon et al., 2019). From this point of view, a crucial challenge is to replace the default semantics of BIM with a more appropriate one allowing experts to organize and relate the heterogeneous data of historical buildings while taking into account all phases of the restoration/conservation process.

Ontologies make an essential contribution in this regard. An ontology is «a conceptual grid which we superimpose to various possible states of affairs» (Guarino, Giaretta, 1995), a hermeneutic process to collect information about a particular reality in orderly and logically linked forms. Today ontologies have found a wide range of applications. The analysis of the state of the art acknowledged the presence of previous researches aimed at establishing an ontology-based framework for modelling architectural knowledge (Fiorani, Acierno, 2017) starting from the most elaborated ontology for the integration of cultural heritage information, that is the CIDOC-Conceptual Reference Module, now ISO 21127:2014 (Doerr, 2009). According to the above-mentioned study, the semantic domains for architecture heritage are essentially four: the artefact, its lifecycle, the investigation process and the involved actors, within each of which there are classes, properties and relationships proper of any ontology.

Since the ontology-based modeling is conceptual and not visual, it is more appropriate than ever to integrate it with the (H)BIM modeling, which has a distinctly graphic and visual-descriptive vocation. Anyway, the problem of the automatic connection between the ontology-based modeling and the BIM one, which is essential due to the complexity of the architectural heritage, is still an open topic today, although the implementation of a specific platform able to translate the two modeling systems into a homogenous format enabling correspondences between them is currently in progress (Simeone et al., 2019).

Therefore, the present research aims to provide its own contribution in this specific issue, developing a possible way to synchronize these two ways of representing architectural heritage by supporting interoperability between software in full compliance with conservation needs.

\section{CASE STUDY AND WORKFLOW}

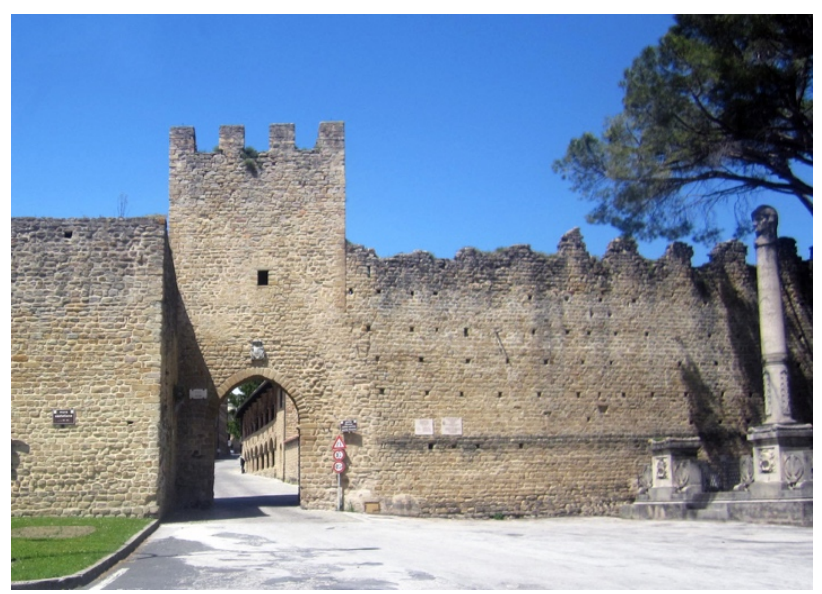

Figure 1. Porta Picena and adjacent curtain walls (ante 2016, (C) authors).

The town of San Ginesio rises on the top of the homonymous hill, at about $700 \mathrm{~m}$ above sea level, close to Macerata in the Marche region (Italy). The town was funded on the remains of Roman settlements, then razed to the ground during the Germanic invasions. The early town centre dates back to the 
$10^{\text {th }}$ century, while the city walls are from the $13^{\text {th }}$ century. In particular, the first defensive city walls were extended in 1250 getting their current configuration at the end of the century.

The city walls were built of square sandstone blocks and still today present an irregular planimetric feature well-suited to the orography of the site and marked by a system of fortified towers including four town gateway towers (Salvi, 1889; Mauro, 1998). Over the centuries, the city walls of San Ginesio were affected by works of transformation, partial reconstruction and restoration, which modified their physical consistency and image. The last earthquake in 2016 further damaged the architectural structures, only temporarily secured for now. As already mentioned, this study focused on the Porta Picena and the adjacent curtain wall (Fig.1). The selected portion can be considered one of the most significant being Porta Picena the main town gateway tower and the most affected by transformations over time, including the 1887 restoration, which involved the complete reconstruction of the crenellation as well as the 2018 post-earthquake safety works.

Applying it to this case study, the workflow of the present research can be summarized in four key steps as follows (Fig.2):

- the data acquisition consisting of survey and analysis of the state of conservation of the selected portion;

- the ontology formalization to properly represent the methodological sequences of the conservation process;

- the ontology-led 3D modeling by a side-by-side approach to synchronize different systems of representing reality;

- finally, the data enrichment of the parametric model.

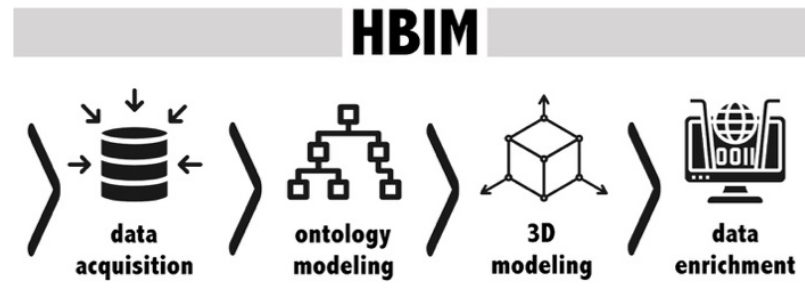

Figure 2. The research workflow (ㄷ authors).

\section{SURVEY AND ANALYSIS OF THE STATE OF CONSERVATION}

\subsection{Data acquisition and processing}

The work started with the acquisition of geometric and photogrammetric data using advanced geomatics technologies: the UAV (Unmanned Aerial Vehicle) digital photogrammetry and the 'handheld' SLAM (Simultaneous Localization And Mapping) laser scanner, which speedily achieve good results both in terms of resolution and accuracy. This kind of technologies are complementary to one another and their combination allows to create high-quality $3 \mathrm{D}$ recordings and representations (Bayram et al., 2015). The accuracy of the 3D point cloud of the city walls was obtained with a detail suitable for conservation activities, in particular for material and decay analysis.

The data acquisition lasted three days and began with the reference system definition. For the topographic survey, a GPT$3105 \mathrm{~N}$ was used as Total Station. The targets placed on the ground were acquired by the GPS HiPer HR with RTK (Real Time Kinematic) method.

The photogrammetric survey of the city walls was performed through a DJI Spark MMA1 drone and its integrated RPAS
(Remotely Piloted Aircraft Systems) camera. Photos were shot in different grades: nadir direction, $30^{\circ}$ and $45^{\circ}$ from the horizon, and frontal direction, covering a global field of view of $180^{\circ}$ and guaranteeing a high number of tie points (Azzola et al., 2019). The survey was carried out at a constant distance of about $30 \mathrm{~m}$ between RPAS camera and the wall, carefully evaluating both the flight time and the global number of shots required to cover the entire city walls surface, and obtaining an average GSD (Ground Sample Distance) of $4 \mathrm{~cm}$. Agisoft Metashape version 1.5.3 was the selected software for the image processing. The following image shows the resulting photogrammetric dense cloud of the selected city walls portion; it was obtained by the Structure-from-Motion technique using the Batch Process tool. (Fig.3).

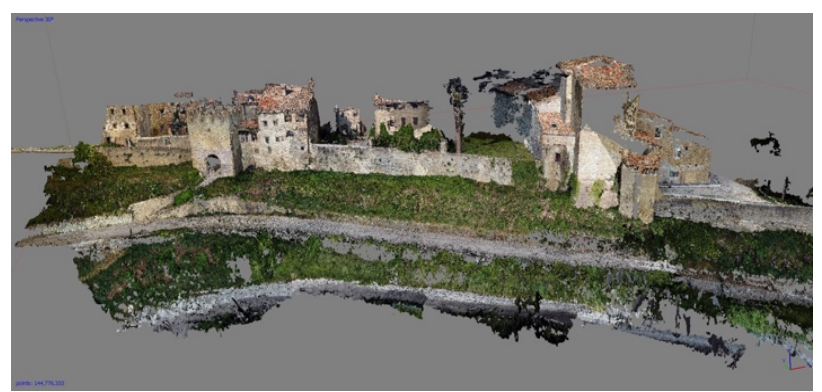

Figure 3. Dense cloud of the selected city walls portion elaborated with Agisoft Metashape software (C) authors).

In addition, a survey campaign with the SLAM MLS (Mobile Laser Scanner) KAARTA Stencil 2 was planned in order to obtain 3D point clouds of the city walls. As this kind of survey involves long walks, the laser scanner was installed on a small pole that the user held with hands during the walking route. The in-use system was Velodyne VLP- 16 with a $360^{\circ}$ field of view having a $30^{\circ}$ azimuthal and opening with a band of 16 scan lines; the laser accuracy range was $\pm 30 \mathrm{~mm} / \pm 1$.2in. The survey tests were performed according to closed paths (close-loop) (Bronzino et al., 2019) between interior and exterior sides of the city walls walking through the gateway tower (Fig.4). For the post-processing elaboration and alignment, the $3 \mathrm{D}$ point cloud analysis was performed using CloudCompare.

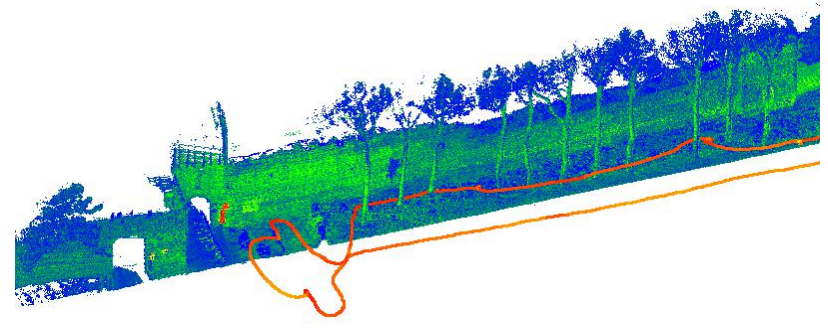

Figure 4. 3D point cloud generated by KAARTA Stencil 2 (C) authors).

\subsection{Decay analysis}

The 2016 seismic events made the analysis of the state of conservation of the city walls a priority for an adequate conservation project that would also take into account the safety works carried out in the aftermath of the earthquake. From the methodological point of view, inspection activities were based on a direct observation through which decay phenomena were documented also highlighting their level of criticality to be subsequently matched to priorities for action. 
With regard to the Porta Picena and the adjacent curtain wall, the analyses revealed a synoptic picture of localised cracks and deformations, features induced by material loss, in particular the differential erosion of the mortar being the wall ridges completely unprotected, partial discolorations, deposits and moist areas, as well as biological colonisations mostly localised in the lower part of structures. In addition, the upper part of the gateway tower, including the crenellation, was temporarily secured by means of a system of steel cables to contain any sagging or even collapsing.

The graphic output was drafted according to the traditional 2D representation and to the existing lexicons provided by the main national and international Institution for Cultural Heritage Protection (the Italian Normal 1/88 - Alterazioni macroscopiche dei materiali lapidei: lessico and its updating UNI 11182:2006, as well as the ICOMOS-ISCS Illustrated glossary on stone deterioration patterns).

The analysis of the state of conservation of the city walls represented a vital knowledge step for planning forthcoming interventions. For this study, the possibility to collect all these data into an information system enriching a 3D virtual model became a fundamental goal in order to support the construction and implementation of a preventive and planned conservation program for this heritage site.

\section{HBIM IMPLEMENTATION}

\subsection{Ontology-based modeling}

Once survey and analysis of the state of conservation of the city walls were completed, an ontology to adequately represent the historical architecture was formalized.

This ontology was based on the above-mentioned researches (Fiorani 2017; Acierno, 2017) and aimed at reproducing, as consistently as possible, the logical structure characterizing the architecture conservation process in the HBIM environment. The idea was therefore to formalize the knowledge of the built heritage by re-proposing, on a conceptual level, all propaedeutic steps for understanding, preserving and managing heritage site in the medium-long term.

As already stated in section 3, four semantic domains were defined: the artefact, the lifecycle, the investigation process and the involved actors; they can be deduced from the reference studies by introducing minimum adjustments.

The artefact consists of twofold classes: spatial and construction classes. On the one hand, the first ones characterize function, typology and organization of the architectural space and are divided into spatial complexes, spatial units and spatial components. On the other hand, construction classes feature the building from a technological point of view consisting of construction units (i.e. foundations, vertical, horizontal and connecting structures), in turn articulated in construction components (i.e. structural/nonstructural vertical and horizontal components, reinforcing components, but also communication components such as stairs, doors and windows, and architectural components), each of which made of construction elements (describing all types of technological elements) as well as of construction materials (e.g. brick, sand, lime, concrete and so on). The structure of the construction classes here presented also reflects that established by the Guidelines for the preventive and planned conservation of the architectural heritage (Della Torre, 2002).

The investigation process includes cognitive and interpretative activities for an exhaustive knowledge of the artefact. This domain is described by two key classes, namely that of direct analysis (geometric survey, material, stratigraphic, diagnostic and decay analysis) for each of which methods, tools and results are also stated, and that of indirect analysis (bibliographic, archival and iconographic research, etc.).

Furthermore, the lifecycle represents the physical and functional transformations of the artefact; in this way space, materials, and time are directly connected according to the event-centred methodological approach of the CIDOC-CRM (Doerr et al., 2020). Finally, the actors domain (professionals, building owners, scholars and so on) concerns subjects that were or will be involved in the lifecycle of the architectural heritage, as regards transformation, study, restoration and management phases.

This described general ontology was then applied to the case study. The city walls as a whole were described as an urban fortified system, composed of curtain walls and towers. Later focusing on the Porta Picena and the adjacent curtain wall, the construction aspects were defined, divided them into square sandstone walls connected with lime mortar, two slabs (a stone vault and a wooden flat slab), the wooden stairs to entrance the gateway tower and all reinforcing elements resulting from previous restoration works. Due to reasons already explained, in the investigation process maximum attention was given to the direct analysis of the decay, pointing out methods, tools, results, and involved actors.

At the end of the ontology-based modeling, the problem of merging this conceptual scheme with the HBIM working space came up. As interoperability between ontology and BIM software is not yet an automatic process, the ontology was implemented directly in Revit, leveraging the general threelevel hierarchy of both modelling system: class $>$ sub-class $>$ entity for the ontology environment and family $>$ family type $>$ instance for the BIM one, as it is described in section 6.2 (Simeone et al., 2019). In this way, the ontology-based modeling was not imported into Revit but served as a guiding principle for the $3 \mathrm{D}$ modeling and the subsequent phase of data enrichment.

\subsection{D modeling and data enrichment}

As soon as the ontology was defined, the next step consisted in creating a HBIM model of the gateway tower and adjacent curtain wall, modeling each building component individually and using the point cloud from geomatics survey as well as information from historical research as references.

The ontology-based data enrichment was carried out in a second phase, which will be detailed below. The final result was an early integrated and complex model, including both geometrical and non-geometrical data, resulting in a real three-dimensional database for supporting heritage conservation process.

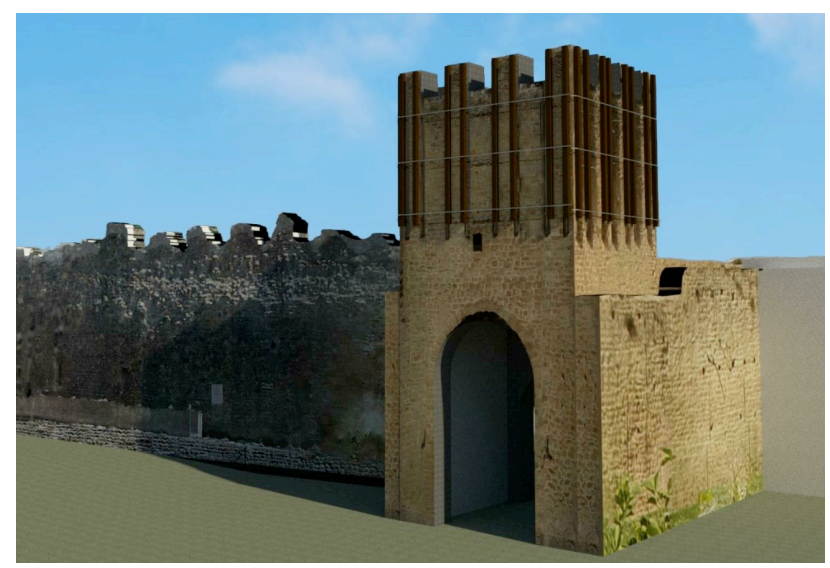

Figure 5. The textured $3 \mathrm{~d}$ model of Porta Picena and the adjacent wall (C) authors). 
Once the first modeling phase was completed in Revit, the modelled elements were inserted by means of 'loadable families'; for instance, they were windows or doors and damaged parts due to the passage of time. In Revit, 'loadable families' tool permits to satisfy any customization requirement, for this reason it is fundamental for representing architectural heritage. These types of families are not a default setting in the Revit project environment; therefore, they have to be loaded from external libraries and edited in the 'family editor'. This latter allows to select an unlimited number of parameters and relationships as well as to define building geometry, appearance and features for a very complete customization. Leveraging this tool, the geometrical model was refined, and the profile of each masonry was reproduced in order to make it coherent with the artefact current state of conservation. Subsequently, textures from photogrammetric survey were applied (Fig.5).

The described 3D model could be considered well-structured and quite truthful, but it was defined only by geometric and dimensional information adding material attributes as deduced from the photos. The main goal of this project was rather to obtain a 3D model able to record all heterogeneous data collected within the ontology scheme. Thus, on the one hand a knowledge-rich ontology was designed (section 6.1), but on the other the model developed in Revit did not allow a direct link to this complex system of data (Garozzo et al., 2017). In the literature there are no examples or cases where it occurs, this is because Revit, but more generally BIM software, has a very different purpose than describing the ontological structure of an existing artefacts. So, an alternative solution to overcome this limitation was studied.

To test the integration of the ontology-based model into BIM, the selected focus was on the decay analysis within which crucial relationships emerge, such as the link between materials, degradation phenomena (including causes and effects) and subsequent interventions.

The representation of decay phenomena in BIM environment could be addressed in different ways (Brumana et al., 2017; Malinverni et al., 2019). Since one of the key issues of this work was the creation of queryable objects, which serve as a collection of interoperable semantic data also available via the $3 \mathrm{~d}$ model, the strategy was to define ad hoc families able to adapt the 3D model and ontology by varying its parameters.

Due to the complex geometry and repetitiveness of decay phenomena, the 'decay family' was not represented as a single family in Revit. For this reason, the use of a 'nested family' capable to group the individual modelled families was the key. This option not only allows users to generate a family containing others, but it is useful for creating general parameters applied to all individual elements and for formulating future queries within software.

In addition, these types of families here representing the decay analysis were then placed on another family hosting them, which in this work was the 'wall family'. Being part of a hosting family, they were directly linked to and affected by it. For example, if the wall was erased, the decay on it disappeared. This relationship between families could be subsequently verified in data-tables in which construction information regarding the wall (materials and techniques) and decay information describing its current state of conservation were systematized. Graphically, elements concerning the 'decay family' were displayed as a transparent veil on the 3D model of the city walls, as the following figure make it clear (Fig.6).

In order to implement the described ontology, two plug-ins were used: DB Link and Dynamo allowing Revit to perform functionalities unsupported by default commands. Revit DB Link is an add-in developed by Autodesk that supports bidirectional interoperability, moving data from and into Revit.
Dynamo, on the other hand, is an extremely flexible open source visual programming environment capable to formulate customized algorithms (procedures or formulas to solve problems) for data processing and the creation of geometries by means of graphical user interface blocks.

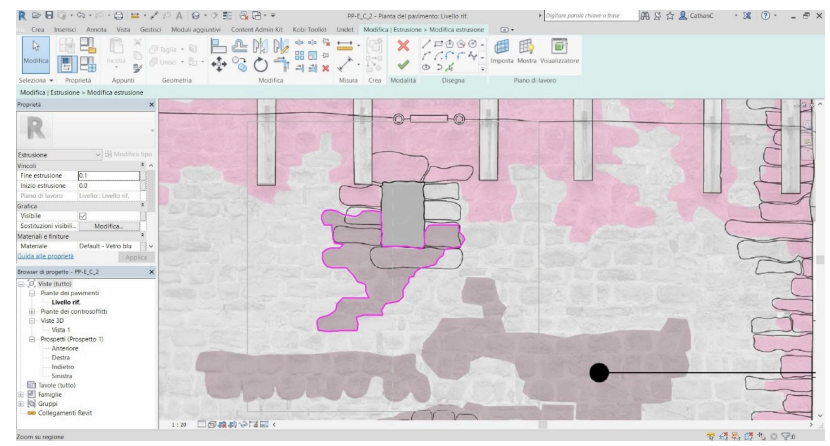

Figure 6. Graphic representation of the decay on the 3D model of the city walls (C) authors).

Dynamo is often used for several purposes, especially to obtain the automatic creation of shared parameters and therefore to facilitate and speed up the parameter creation process.

The final achievement in using these two plug-ins was a faithful representation of the architectural heritage decay, as it was described within the ontology. To make it possible, the tripartite hierarchical structure of both conceptual and 3D representation systems was essential. Stressing this homologous 3-level structure, the ontology information hierarchy (class $>$ sub-class $>$ entity) was manually transferred in Revit (family > family type $>$ instance). First of all, semantic contents of the artefact domain were modelled, in particular construction classes. For example, the vertical structures (construction unit in the ontology scheme) became a family in Revit within which several types and instances made it possible to respectively distinguish the ontology construction elements and materials. Then, as already illustrated, the described and data enriched 'wall family' hosted the 'decay nested family' expressing the fundamental relationship between materials and decay phenomena with all specificities of this analysis. All these semantic contents were uploaded using 'shared parameters' acting as carriers of information.

In this perspective, a unique identification code (ID) was additionally assigned to all ontological data; at the same time, references to the host family were added. To better explain how data were constructed, it is useful to consider a very practical example of a decay family element which, in turn, is part ('host') of the wall family. Its ID was designed in order to transfer specific properties of the element, as well as the ontology domain to which it belongs (Di Stefano et al., 2019). For instance: 'DInvPro_DA_erosion' is the decay element ID, informing users that it belongs to the investigation process domain (DInvPro), results from the decay analysis (DA) and identifies an erosion; while 'DAr_M Square sandstone blocks' is its host wall ID, informing users that it belongs to the artefact domain (DAr) and it is a masonry (M) made of square sandstone blocks.

Working in this way means that data belonging to all described elements could be also recognized even once exported from Revit. Using exported tables, in fact, it is possible to identify the ontology logic workflow. Therefore, these parameters have to be compiled according to the ontology-based modeling.

Being a mechanical process within a BIM workspace, it could take a long time and be conditioned by human error during the compilation phases. To overcome this problem, the solution was 
to compile it outside Revit. The selected add-in tool was DB Link plug-in allowing users to export the Revit parameters and making them available in an external database such as MS Excel or MS Access. Once the database was compiled according to the ontology, the final file was imported again by DB Link into the BIM software which updated the externally operated changes also in the Revit project.

All parameters, thus compiled and collected within the project, became also easily accessible from the 3D model. However, in order to make them more readable they were grouped in schedules or otherwise externally exported.

Working outside Revit also demonstrated the advantage of enabling external users, who have no specific expertise in BIM software, to collaborate with other stakeholders in a simpler and more intuitive work environment, such as a spreadsheet or Access database. Moreover, query, spreadsheet and database functions could be performed using data coming from the 3D model.

Finally, it is important to point out that decay elements greatly increased the detail of the 3D model, since it is often a question of representing very small and irregular areas, with a subcentimetric accuracy. This required the achievement of a level of development (LOD) at least of LOD E (according to the Italian standard UNI 11337-4), corresponding to LOD 350 in the USA reference system or to LOD 5 in the UK PAS11922:2013 (Bruno et al., 2019).

At the end of this process, a complete database regarding the state of conservation of the selected portion of the city walls of San Ginesio was developed. This is and will be a crucial tool for planning future conservation interventions as well as for constantly monitoring that historical site in compliance with architectural heritage ontological standards.

\section{CONCLUSIONS}

\subsection{Main achievements}

The proposed methodology included different phases, each of which considered the in-use technologies as key enablers to acquire, hierarchically order, model, enrich and finally query and share the knowledge of the city walls of San Ginesio.

The present study developed an integrated approach to architectural knowledge modelling combining an empirical (ontology) and visual and descriptive (3D model) representation of a historical site as a way to enhance knowledge acquisition, representation and management in built heritage processes.

This knowledge-led strategy moved from survey to the implementation of HBIM, that will become soon compulsory for the management of existing buildings belonging to public administrations.

The objective was to exploit the potential of HBIM without renouncing the complexity of architectural heritage. A first key result was about a way to overcome the impossibility of directly and automatically importing an ontology scheme in a parametric software. Another goal concerned the collection and hierarchical organization of queryable data to guide long-term conservation processes resulting from a hermeneutic process based on knowledge.

\subsection{Future works}

As in any scientific research, some technical aspects are still open matters, such as the long timescale of the manual enrichment phase, which is nevertheless balanced by the advantages for heritage conservation and management according to a flexible and constantly updated scheme. Further specific in-depth researches will be conducted in order to improve this strategy for architectural knowledge modelling, as well as the transition from an architectural to an urban scale as this specific case study suggests.

\section{ACKNOWLEDGEMENTS}

The authors would like to thank Ordnance Survey GB (www.ordnancesurvey.co.uk) and 1Spatial (www.1spatial.com/) for sponsoring the publication of this paper.

\section{REFERENCES}

Acierno, M. 2017. Un modello di rappresentazione per il restauro. Il caso dell'Oratorio di S. Saba a Roma. In Della Torre, S. (ed), Modellazione e gestione delle informazioni per il patrimonio edilizio esistente - Built Heritage Information Modelling/Management BHIMM. Galazzano, Edizioni IMRead.

Acierno, M., Cursi, S., Simeone, D., Fiorani, D., 2017. Architectural heritage knowledge modelling: an ontology-based framework for conservation process. Journal of Cultural Heritage, 24, 124-133.

https://doi.org/10.1016/j.culher.2016.09.010

Acierno, M., Fiorani, D., 2019. Innovative tools for managing historical buildings: the use of geographic information system and ontologies for historical centers. Int. Arch. Photogramm. Remote Sens. Spatial Inf. Sci., 42, 21-27. doi.org/10.5194/isprsarchives-XLII-2-W11-21-2019.

Arayici Y., 2008. Towards building information modelling for existing structures. Structural Survey, 26(3), 210-222. doi.org/10.1108/02630800810887108.

Azzola, P., Cardaci, A., Mirabella Roberti, G., Nannei, V.M., 2019. UAV photogrammetry for cultural heritage preservation modeling and mapping Venetian Walls of Bergamo. Int. Arch. Photogramm. Remote Sens. Spatial Inf. Sci., 42, 45-50. https://doi.org/10.5194/isprs-archives-XLII-2-W9-45-2019.

Banfi, F., Oreni, D., 2020. Virtual Reality (VR), Augmented Reality (AR), and Historic Building Information Modeling (HBIM) for built heritage enhancement: from geometric primitives to the storytelling of a complex building. In Impact of Industry 4.0 on Architecture and Cultural Heritage, IGI Global, 111-136. doi.org/10.4018/978-1-7998-1234-0.ch005.

Bayram, B., Nemli, G., Özkan, T., Oflaz, O.E., Kankotan, B., and Çetin, I., 2015. Comparison of laser scanning and photogrammetry and their use for digital recording of cultural monument case study: byzantine land walls - Istanbul. ISPRS Ann. Photogramm. Remote Sens. Spatial Inf. Sci., 2, 17-24. https://doi.org/10.5194/isprsannals-II-5-W3-17-2015.

Biagini, C., Capone, P., Donato, V., Facchini, N., 2016. Towards the BIM implementation for historical building restoration sites. Automation in Construction, 71, 74-86. doi.org/10.1016/j.autcon.2016.03.003.

Bronzino, G.P.C., Grasso, N., Matrone, F., Osello, A., Piras, M., 2019. Laser-visual-inertial odometry based solution for 3D heritage modeling: the Sanctuary of the Blessed Virgin of Trompone. Int. Arch. Photogramm. Remote Sens. Spatial Inf. Sci., 42, 215-222. https://doi.org/10.5194/isprs-archives-XLII-2W15-215-2019. 
Brumana, R., Della Torre, S., Oreni, D., Previtali, M., Cantini, L., Barazzetti, L., Franchi, A., Banfi, F., 2017. HBIM challenge among the paradigm of complexity, tools and preservation: the Basilica di Collemaggio 8 years after the earthquake (L'Aquila). Int. Arch. Photogramm. Remote Sens. Spatial Inf. Sci., 42, 97104. doi:10.5194/isprs-archives-XLII-2-W5-97-2017.

Bruno, N., Roncella, R., 2019. HBIM for conservation: A new proposal for information modeling. Remote Sensing, 11(15), 124. https://doi.org/10.3390/rs11151751.

Chiabrando, F., Colucci, E., Lingua, A., Matrone, F., Noardo, F., Spanòa, A., 2018. A European Interoperable Database (EID) to increase resilience of cultural heritage. Int. Arch. Photogramm. Remote Sens. Spatial Inf. Sci., 42, 151-158. https://doi.org/10.5194/isprs-archives-XLII-3-W4-151-2018.

Della Torre, S., 2012. La conservazione programmata del patrimonio storico architettonico. Linee guida per il piano di manutenzione e il consuntivo. Milano, Edizioni Angelo Guerini e Associati.

Della Torre, S. 2017. Un bilancio del progetto BHIMM. In Della Torre, S. (ed), Modellazione e gestione delle informazioni per il patrimonio edilizio esistente - Built Heritage Information Modelling/Management BHIMM. Galazzano, Edizioni IMRead.

Di Giulio, R., Boeri, A., Longo, D., Gianfrate, V., Boulanger, S.O., Mariotti, C., 2019. ICTs for Accessing, Understanding and Safeguarding Cultural Heritage: the experience of INCEPTION and ROCK H2020 Projects. International Journal of Architectural Heritage, 1-19.

https://doi.org/10.1080/15583058.2019.1690075.

Di Stefano, F., Malinverni, E.S., Pierdicca, R., Fangi, G., Ejupi, S., 2019. HBIM implementation for an ottoman mosque. case of study: Sultan Mehmet Fatih II Mosque in Kosovo. Int. Arch. Photogramm. Remote Sens. Spatial Inf. Sci., 42, 429-436. https://doi.org/10.5194/isprs-archives-XLII-2-W15-429-2019.

Doerr, M. 2009. Ontologies for cultural heritage. In Handbook on ontologies. Berlin, Heidelberg, Springer, 463-486.

Doerr, M., Bekiari, C., Bruseker, G., Ore C., Stead, S., Velios T., 2020. Definition of the CIDOC Conceptual Reference Model, Volume A. ICOM-CIDOC. http://www.cidoc-crm.org.

Dore, M., Murphy, M., 2012. Integration of Historic Building Information Modelling (HBIM) and 3D GIS for Recording and Managing Cultural Heritage Sites. Virtual Systems in the Information. VSMM 2012, 18th International Conference on Virtual Systems and Multimedia, Milan, IEEE, 369-376. doi.org/10.1109/VSMM.2012.6365947.

Dore, C., Murphy, M., 2017. Current state of the art historic building information modelling, Int. Arch. Photogramm. Remote Sens. Spatial Inf. Sci., 42, 185-192. https://doi.org/10.5194/isprs-archives-XLII-2-W5-185-2017.

Fiorani, D., 2017. La modellazione della conoscenza nel restauro. Uno sviluppo per il BHIMM. Problematiche generali e il caso-studio di San Saba in Roma. In Della Torre, S. (ed), Modellazione e gestione delle informazioni per il patrimonio edilizio esistente - Built Heritage Information Modelling/Management BHIMM. Galazzano, Edizioni IMRead.
Fiorani, D., Acierno, M., 2017. Conservation Process Model (CPM): a twofold scientific research scope in the information modelling for cultural heritage. Int. Arch. Photogramm. Remote Sens. Spatial Inf. Sci., 42, 283-290.https://doi.org/10.5194/isprsarchives-XLII-5-W1-283-2017.

Garagnani S., Manferdini A.M., 2013. Parametric Accuracy: Building Information Modelling process applied to the Cultural Heritage preservation. Int. Arch. Photogramm. Remote Sens. Spatial Inf. Sci., 40, 87-92. doi.org/10.5194/isprsarchives-XL-5W1-87-2013.

Garozzo, R., Murabito, F., Santagati, C., Pino, C., Spampinato, C., 2017. CulTO: an ontology-based annotation tool for data curation in cultural heritage. Int. Arch. Photogramm. Remote Sens. Spat. Inf. Sci, 42, 267-274. https://doi.org/10.5194/isprsarchives-XLII-2-W5-267-2017.

Guarino, N., Giaretta, P., 1995. Ontologies and knowledge bases. In Towards very large knowledge bases, Amsterdam, IOS.

Logothetis, S., Delinasiou, A., Stylianidis, E., 2015. Building information modelling for cultural heritage: a review. ISPRS Annals of the Photogramm. Remote Sens. Spatial Inf. Sci., 2(5), 177. doi:10.5194/isprsannals-II-5-W3-177-2015.

Malinverni, E.S., Mariano, F., Di Stefano, F., Petetta, L., Onori, F., 2019. Modelling in HBIM to document materials decay by a thematic mapping to manage the cultural heritage: the case of 'Chiesa della Pietà' in Fermo. Int. Arch. Photogramm. Remote Sens. Spatial Inf. Sci., 42, 777-784.https://doi.org/10.5194/isprsarchives-XLII-2-W11-777-2019.

Mauro, M., 1998. Castelli, rocche, torri, cinte fortificate delle Marche, v.4. Roma, Istituto Italiano dei Castelli.

Murphy, M., McGovern, E., Pavia, S., 2009. Historic building information modelling (HBIM). Structural Survey, 27(4), 311327. doi.org/10.1108/02630800910985108.

Noardo, F., 2016. Architectural Heritage Ontology-Concepts and Some Practical Issues. In International Conference on Geographical Information Systems Theory, Applications and Management. SCITEPRESS, V2, 168-179.

Pili, A., 2019. BIM process, ontologies and interchange platform for cultural architectural heritage management: State of art and development perspectives. Int. Arch. Photogramm. Remote Sens. Spatial Inf. Sci., 42, 969-973.

doi.org/10.5194/isprs-archives-XLII-2-W11-969-2019.

Quattrini, R., Malinverni, E.S., Clini, P., Nespeca, R., Orlietti, E., 2015. From TLS to HBIM. High quality semantically-aware 3D modeling of complex architecture. Int. Arch. Photogramm. Remote Sens. Spatial Inf. Sci., 40, 367-374. doi:10.5194/isprsarchives-XL-5-W4-367-2015.

Quattrini, R., Pierdicca, R., Morbidoni, C., 2017. Knowledgebased data enrichment for HBIM: Exploring high-quality models using the semantic-web. Journal of Cultural Heritage, 28, 129-139. doi.org/10.1016/j.culher.2017.05.004.

Salvi, G.C., 1889. Memorie storiche di San Ginesio in relazione con le terre circonvicine. Tipografia Savini. 
Simeone, D., Cursi, S., Acierno, M., 2019. BIM semanticenrichment for built heritage representation. Automation in Construction, 97, 122-137.

doi.org/10.1016/j.autcon.2018.11.004.

Simeone, D., Cursi, S., Toldo, I., Carrara, G., 2014. B(H)IM Built Heritage Information Modelling. Extending BIM approach to historical and archaeological heritage representation. ECAADe, 1, 613-622.

Spallone, R., Piano, A., Piano, S., 2016. BIM and cultural heritage: multi-scalar and multi-dimensional analysis and representation of an historical settlement. DISEGNARECON, 9(16), 13.1-13.12.

Volk, R., Stengel, J., Schultmann F., 2014. Building Information Modelling (BIM) for existing buildings - Literature review and future needs, Automation in Construction, 38, 109127. doi.org/10.1016/j.autcon.2013.10.023. 